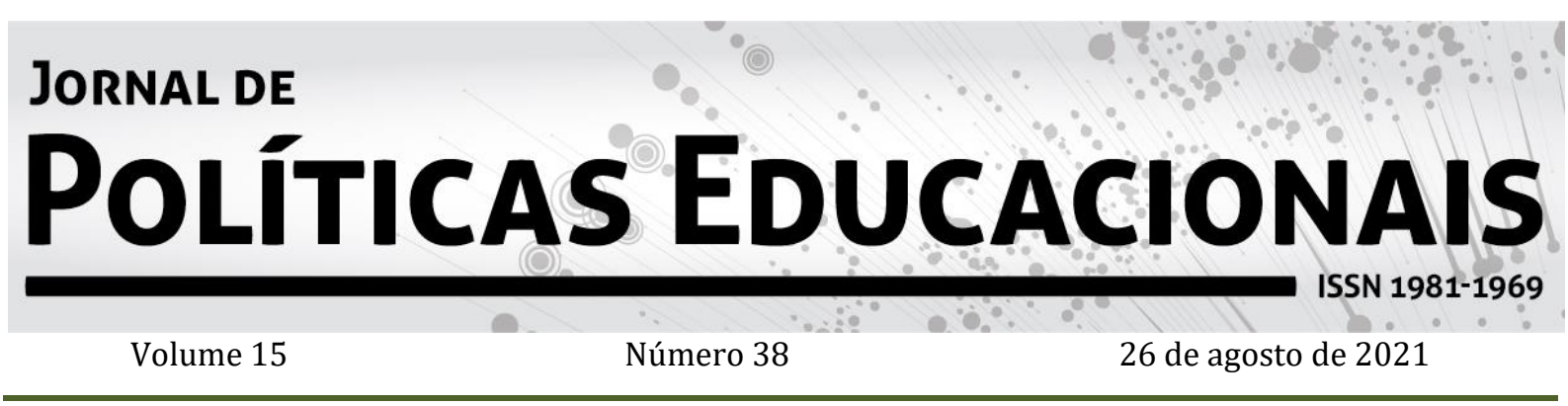

\title{
A organização e ação do movimento empresarial Todos pela Educação durante a pandemia da COVID-19
}

\section{The organization and action of the Todos pela Educação [All For Education] business movement during the Covid-19 pandemic}

\section{La organización y la acción del movimiento empresarial Todos Pela Educação durante la pandemia de COVID-19}

\author{
Lucia Hugo Ucrak ${ }^{1}$ \\ Liane Maria Bernardi ${ }^{2}$
}

Citação: UCZAK, L.H; BERNARDI, L.M. A organização e ação do movimento empresarial Todos pela Educação durante a pandemia da COVID-19. Jornal de Políticas Educacionais. V. 15, n. 38. Agosto de 2021.

http://10.5380/ipe.v15i0.79504

Resumo: Este artigo tem como objetivo apresentar algumas discussões sobre como o movimento empresarial Todos pela Educação - TPE - tem se articulado, no ano de 2020, enquanto movimento de classe e sua ação junto à organização de políticas educacionais nesse período de pandemia. 0 presente estudo explora evidências dessa ação a partir das Notas Técnicas sobre ensino a distância na educação básica e retorno às aulas presenciais frente à pandemia da COVID-19 divulgadas pelo movimento. Aborda, nesse sentido, sua ação na elaboração da política de financiamento do novo Fundo de Manutenção da Educação Básica - Fundeb, a partir do documento Educação Já, destacando sua atuação junto ao Congresso Nacional. Fontes bibliográficas e de pesquisa documental evidenciam que o movimento empresarial Todos pela Educação, representante do setor privado mercantil, logo após a suspensão das aulas presenciais, rapidamente se reorganizou e chamou para si a liderança e a coordenação das políticas educacionais, buscando construir, na opinião pública, o consenso da garantia dos direitos de aprendizagem e, ao mesmo tempo, ampliando a ação do mercado na educação pública brasileira, tanto na proposição quanto na implantação de políticas-direcionadas ao avanço da Educação a Distância e no financiamento da educação.

Palavras-chave: Todos Pela Educação, Pandemia, Políticas educacionais, Financiamento.

Abstract: This article aims to present some discussions about how the Todos pela Educação (TPE) [All

\footnotetext{
${ }^{1}$ Doutora em Educação. Professora na Universidade Feevale. Integra o grupo de pesquisa GPRPPE/UFRGS. Porto Alegre. Rio Grande do Sul. Brasil Orcid: https://orcid.org/0000-0003-1336-0083 E-mail: lucia.hugo@yahoo.com.br

${ }^{2}$ Doutora em Educação. Professora aposentada da Rede Pública Municipal de Porto Alegre-RS. Integra o grupo de pesquisa GPRPPE/UFRGS. Orcid: https://orcid.org/0000- 0001-5915.7318 E-mail: lianebernardi@gmail.com
} 


\section{JORNAL DE Políticas EducacionaIS \\ ISSN 1981-1969}

For Education business movement has been articulating in the year 2020, itself as a class movement, as well as its action along with the organization of educational policies in this period of the pandemic. This study explores the evidence of this action based on the Technical Notes - on distance learning in basic education and return to presencial classes in the context of the covid-19 pandemic - that were released by the movement. In this sense, your action in the elaboration of the financing policy of the new Fundo de Manutenção da Educação Básica (Fundeb) [Basic Education Maintenance Found], based on the document Educação Já [Education Now], highlighting its acting along with the National Congress. Bibliographic sources and documentary research, is evidence that the TPE business movement, representative of the private market sector, right after the suspension of presencial classes was quickly reorganized and called for itself the leadership and the coordination of educational policies. It was done in order to build a consensus of the public opinion on guaranteeing learning rights and, at the same time, to expand the action of the market in the Brazilian public education, both in the proposition and in the implementation of policies that aim at the implementation of e-learning, and in the financing of education.

Keywords: All For Education, Pandemic, Educational policies, Financing.

Resumen: Este artículo tiene el objetivo de presentar algunas discusiones sobre como el movimiento empresarial "Todos pela Educação" - TPE - se ha articulado, en el año de 2020, como movimiento de clase y su acción junto a la organización de políticas educativas durante el período de la pandemia. El presente estudio explota evidencias de esa acción a partir de las Notas Técnicas sobre enseñanza a distancia en la educación básica y regreso a las clases presenciales frente a la pandemia de COVID-19 divulgadas por el movimiento. Aborda, en este sentido, su acción en la elaboración de la política de financiación del nuevo Fondo de Mantenimiento de la Educación Básica - Fundeb, a partir del documento "Educação já", destacando su actuación junto al Congreso Nacional. Fuentes bibliográficas y de investigación documental dan evidencia que el movimiento empresarial Todos Pela Educação, representante del sector privado mercantil, inmediatamente después de la suspensión de las clases presenciales, se organizó rápidamente y asumió el liderazgo y la coordinación de las políticas educativas, buscando construir, en la opinión pública, el consenso de garantía de los derechos de aprendizaje y, al mismo tiempo, ampliando la acción del mercado en la educación pública brasileña, tanto en proporción como en la implementación de políticas direccionadas al avance de la Educación a Distancia y la financiación de la educación.

Palabras Clave: Todos Pela Educação; Pandemia; Políticas Educacionales; Financiación.

\section{Introdução}

A classe empresarial manifesta seu interesse para com a educação brasileira de longa data. Em 2006, foi convocada, pela financeira Itaú Unibanco Participações S. A., a realização da Conferência Ações e Responsabilidade Social em Educação, promovida pela Fundação Lemann, Fundação Jacobs e Grupo Gerdau, com apoio do Programa de Reformas Educacionais para a América Latina - PREAL. Nessa ocasião, constituiu-se o Todos pela Educação - TPE, que, segundo Shiroma, Garcia e Campos (2011, p. 233), foi “criado por um grupo de intelectuais orgânicos do capital”. Desde então, "os empresários se antecipam e pautam a agenda governamental: reafirmam o papel do Estado 


\section{JORNAL DE Políticas Educacionals}

ISSN 1981-1969

redefinindo, no entanto, o sentido e o significado da educação pública" (ibidem, p. 226). 0 TPE propõe a mobilização da iniciativa privada e das organizações sociais do terceiro setor para atuar junto com o Estado no provimento da educação. Em 2014, o TPE tornou-se uma Organização Social sem Fins Lucrativos e constitui-se atualmente como uma rede política que envolve intelectuais, empresas públicas e privadas, cujos interesses heterogêneos articulam-se em torno da intervenção na educação.

Neste artigo, cujo objetivo é mostrar como a classe empresarial se organiza e age na construção de políticas educacionais no Brasil ${ }^{3}$, atualizamos as discussões acerca das ações do setor privado mercantil no período de pandemia da COVID-19. Para tanto, a partir da metodologia de pesquisa bibliográfica e análise documental, apresentamos o movimento empresarial, observando sua atuação, seu discurso e sua proposta de ação junto a dois focos: o primeiro trata das Notas Técnicas sobre ensino a distância na educação básica e retorno às aulas presenciais frente à pandemia da COVID-19 divulgadas, respectivamente, em abril e maio de 2020, pelo TPE; o segundo aborda as propostas educacionais de financiamento no documento "Educação Já", apresentado como interlocução com o Governo para o período entre 2019 e 2022, e as interfaces da ação do movimento na elaboração da política de financiamento do novo Fundo de Manutenção da Educação Básica - Fundeb -. Destacamos que ambos os focos evidenciam a articulação dos membros do TPE, assim como seu protagonismo na proposição e direcionamento das ações, em especial, durante a pandemia da COVID-19 e nos concentramos neles, entre os tantos possíveis, apenas devido ao limite espacial deste estudo.

Adotamos a pesquisa qualitativa e, através de documentos produzidos e publicados no próprio site do movimento, articulamos a análise sobre como estão projetando a ampliação da sua inserção nas políticas educacionais do País, especialmente nesse momento de exceção causado pela pandemia, em que chamam para si a coordenação das ações de enfrentamento da crise. Na pesquisa documental, com base em

\footnotetext{
3 Os dados apresentados neste texto foram coletados até 30 de dezembro de 2020.
} 


\section{JORNAL DE}

\section{Políticas EducacionaIS}

ISSN 1981-1969

Ball (2014), consultamos diversas fontes, como páginas da Internet, vídeos, PowerPoints, webinários, páginas do Facebook, blogs e tweets, além da publicação de entrevistas com pessoas-chave para o tema. 0 autor afirma que a busca e o uso desses materiais são relevantes para a construção das 'redes políticas' e que “juntos estes constituem algo que pode ser chamado de 'método' de 'etnografia de rede' [...] um mapeamento da forma e do conteúdo das relações políticas em um campo particular [...]" (BALL, 2014, p. 28). Embora o objetivo deste estudo não seja o de construir a rede do TPE, nem discutir a etnografia de rede, os procedimentos de coleta de dados utilizados pelo autor e adotados neste artigo foram fundamentais para a elaboração do corpus documental.

Cabe destacar que acompanhamos com atenção os movimentos de classe e ação dos empresários na construção de políticas e, em publicações anteriores, já apresentamos evidências dessa influência do TPE. a) a forte interlocução e ação junto ao Governo Federal, na construção do Plano de Ações Articuladas (PAR), em que participou da elaboração e da execução ao ofertar soluções no Guia de Tecnologias Educacionais4; b) na elaboração do Plano Nacional de Educação (PNE), o qual monitora, através do Observatório do PNE e da publicação do Anuário Brasileiro da Educação Básica - TPE, de responsabilidade conjunta com a editora Moderna, quando se organizaram, se multiplicaram em outros movimentos e passaram a participar da elaboração de políticas educacionais no País, ampliando sua influência e ação. Também já apresentamos como atuou fortemente nas discussões da BNCC, desde sua elaboração, antecipando propostas de implantação, oferecendo, por meio do Movimento pela Base Nacional Curricular MBNC (que possui em sua estrutura maioria de participantes membros e apoiadores do TPE) um manual de execução da BNCC, até a oferta de formação a professores e gestores ${ }^{5}$. Similarmente, já destacamos como estão articulados junto ao Conselho Nacional de Educação - CNE - e nas discussões sobre o Fundeb, através da composição do TPE junto à Frente Parlamentar Mista no Congresso Nacional, que, desde 2019, discute o novo

\footnotetext{
${ }^{4}$ Ver: Rossi, Bernardi, Uczak (2017).

${ }^{5}$ Ver: Rossi, Bernardi, Uczak (2018b)
} 


\section{JORNAL DE}

\section{Políticas EducacionaIS}

ISSN 1981-1969

Fundeb ${ }^{6}$. Em conjunto com a Undime e o Conselho Nacional de Secretários de Educação (Consed), o Centro de Estudos e Pesquisas em Educação, Cultura e Ação Comunitária (Cenpec) e a Fundação Lemann, "fazem parte do Conselho Consultivo da Frente, cujo objetivo é ofertar evidências científicas e da realidade das redes de ensino para os parlamentares" (TPE, 2019). 0 argumento do TPE na apresentação de suas contribuições recai sempre sobre o caráter técnico, científico, baseado em evidências, justificando uma suposta neutralidade pedagógica e ideológica da educação.

Justificamos, assim, a presente pesquisa frente ao imperativo de conhecermos a atuação do TPE na educação brasileira nesse contexto de pandemia e o conteúdo das propostas defendidas pelo Todos. Consideramos as suas ações de classe que disputa um projeto societário e recursos públicos, produzindo e difundindo uma concepção de mundo e lutando para produzir o consenso em torno dela. Para nós, esse conceito de classe baseia-se na concepção de Thompson (1981), que a vê não como categoria, mas como algo que ocorre dentro de um período histórico, que não é estático, mas que é "visível apenas no processo" (WOOD, 2003, p. 77).

Entendemos que a correlação de forças é produtora de consensos em sociedades nas quais a "criação da hegemonia não é algo abstrato, mas produzido através da disputa entre grupos e classes sociais (ROSSI, BERNARDI, UCZAK, 2020, p. 357). Gramsci (2002) ensina-nos, nesse sentido, que é preciso compreender o "grau de homogeneidade e de organização alcançada pelos diversos grupos sociais" (GRAMSCI, 2002, p. 40), seja “como domínio e como direção intelectual e moral" (Ibidem, p. 62). Assim sendo, interessa observarmos a organização e os movimentos realizados pela classe empresarial, representado pelo sujeito TPE, na criação de consensos.

\section{A reafirmação do TPE através das Notas Técnicas sobre ensino a distância na educação básica frente à pandemia da COVID-19}

\footnotetext{
6 Ver: Uczak, Bernardi, Rossi (2019)
} 


\section{JORNAL DE}

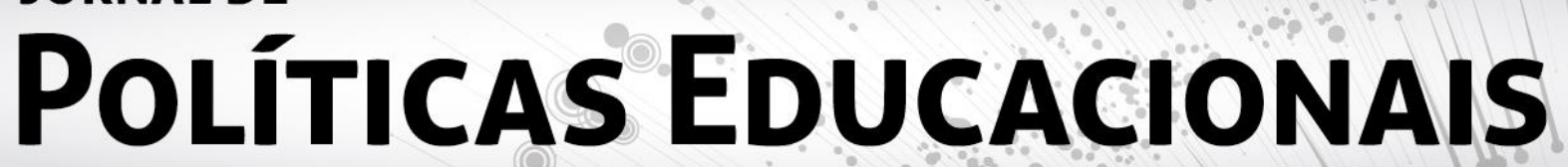

ISSN 1981-1969

Desde o momento da suspensão das aulas presenciais no Brasil, em meados de março de 2020, o TPE tem se colocado como um coordenador de ações em nível nacional para o enfrentamento à pandemia no contexto educacional. Nesse sentido, tem realizado diversas atividades, como participação em programas televisivos, apoio a projetos de lei, seminários e webnários, além da publicação de uma série de documentos em que apresentam suas contribuições sob o argumento de qualificar o debate e subsidiar o poder público.

Em 08 de abril, o TPE promoveu o Webinário "A Educação frente à Pandemia", organizado em conjunto com o Banco Mundial (BM) e o Conselho Nacional de Educação (CNE). 0 debate virtual também contou com a participação de representantes da União Nacional dos Dirigentes Municipais de Educação (Undime) e do Conselho Nacional de Secretários da Educação (Consed). 0 evento propunha discutir os desafios regulatórios e pedagógicos para a educação a distância no período. Priscila Cruz, presidente executiva do Todos, lamentou a falta de proposição e coordenação de políticas por parte do Governo Federal e, ao mesmo tempo, destacou que "talvez um aspecto positivo desse momento seja, por meio da reunião de esforços, criar uma coordenação que pudesse levar esses aprendizados para os anos seguintes" (TPE, 2020a). Ou seja, o TPE "reforçou sua estratégia de reivindicar para si a responsabilidade sobre a educação básica brasileira e atracou como um dos principais articuladores sobre como conduzir a educação na pandemia e no pós-pandemia [...]" (HERDADE, 2020, p. 49).

$\mathrm{Na}$ sequência do webinário, o economista do BM apresentou o documento "Políticas educacionais na pandemia da covid-19: o que o Brasil pode aprender com o mundo?". Segundo João Marcelo, diretor de estratégia política do TPE, o documento foi uma base para a elaboração da primeira Nota Técnica "Ensino a distância na educação básica frente à pandemia da COVID-19", a qual se concentra em quatro aspectos essenciais, a seguir elencados, e foi divulgada naquele mesmo dia.

1. Frente ao atual momento, soluções de ensino remoto podem contribuir e devem ser implementadas, mas têm efeito limitado, sendo preciso normatizar e, desde já, planejar a volta às aulas presenciais. 


\section{JORNAL DE Políticas EduCacionaIS}

ISSN 1981-1969

2. Uma estratégia consistente para o ensino remoto deve buscar mitigar condições heterogêneas de acesso e de desempenho prévio dos estudantes.

3. Ensino remoto não é só aula online. Há diferentes maneiras de estimular a aprendizagem a distância que, se bem estruturadas, podem cumprir mais do que uma função puramente acadêmica.

4. Mesmo a distância, a atuação dos professores é central. (TODOS PELA EDUCAÇÃO, 2020b)

Os aspectos destacados na Nota Técnica estão alinhados à proposta lançada pela UNESCO em março de 2020, com objetivo de formar uma coalizão mundial para acelerar a implantação de soluções de aprendizagem a distância. Ou seja, o TPE arranja e difunde no Brasil as diretrizes que, com apoio do BM e da UNESCO, foram produzidas mundialmente pela coalizão, "sistematizando uma série de discussões e documentos para fomentar não só o ensino remoto como única saída para a crise educacional, mas toda a sua ideologia e pedagogia de mercado" (HERDADE, 2020, p. 49). Há, no mínimo, dois aspectos a considerar nessa afirmação. 0 primeiro é a estratégia de indicar o ensino remoto como 'a única solução possível' para o atendimento educacional. Observe-se que, diferente da educação a distância, que é uma modalidade regulamentada na legislação brasileira, o ensino remoto é mais flexível em termos de ferramentas e estratégias para a 'entrega de conteúdo' aos estudantes. Por outro lado, essa diversidade de estratégias abre a possibilidade para o mercado de tecnologias educacionais, tanto no período atual como no pós-pandemia, ofertar soluções e comercializar com os governos.

0 segundo aspecto a considerar, referido como pedagogia de mercado, indica uma formação aligeirada e direcionada para a formação da classe trabalhadora, a fim de atender as necessidades do mercado de trabalho. Essa proposta vem sendo a alternativa recomendada pelos organismos internacionais como uma medida segura para enfrentamento às recorrentes crises do capitalismo no mundo ocidental. A pedagogia de mercado visa a uma formação pragmática, com foco no desenvolvimento de competências e habilidades para a resolução de problemas de modo ágil e rápido. Isso significa a formação do trabalhador útil e necessário em detrimento da formação do ser social, em uma perspectiva ontológica, prevista nas diretrizes curriculares para a educação básica. 


\section{JORNAL DE}

\section{Políticas EducacionaIS \\ ISSN 1981-1969}

São, pois, dois projetos educacionais, com objetivos distintos, que apresentam mais antagonismos que convergências.

Tanto o webinário quanto o conteúdo da Nota constituíram a base para o Conselho Nacional de Educação emitir, em 28 de abril, o Parecer 05/2020, em que expressou as orientações para "Reorganização do Calendário Escolar e da possibilidade de cômputo de atividades não presenciais para fins de cumprimento da carga horária mínima anual, em razão da Pandemia da COVID-19". São relatores do Parecer, Luiz Roberto Liza Curi, Eduardo Deschamps e Maria Helena Guimarães de Castro (sócia-fundadora do TPE), todos com participação direta nos diversos eventos organizados pelo TPE para o gerenciamento da crise. Consideramos que a trajetória para elaboração do Parecer e o seu conteúdo expressam a liderança do TPE na proposição e coordenação de uma política de governo. Ao mesmo tempo, a omissão do MEC, deixando de exercer seu papel como coordenador da política educacional brasileira, abriu o espaço para que o movimento exercesse essa gestão.

Em 06 de maio de 2020, o TPE publicou a segunda Nota Técnica, chamada "O retorno às aulas presenciais no contexto da pandemia da COVID-19". Para sustentação dos argumentos apresentados, a Nota refere consulta aos especialistas Alexandre Schneider (Ex-secretário Municipal de São Paulo, SP), Alexsandro Santos (Ex-secretário adjunto de Franco da Rocha, SP), Cláudia Costin (Ex-secretária Municipal do Rio de Janeiro, RJ), Raquel Teixeira (Ex-secretária de Educação de Goiás) e Washington Bonfim (Ex-secretário Municipal de Teresina, PI). 0 referido documento destaca três aspectos:

1. As escolas irão se deparar com desafios que só poderão ser enfrentados com o apoio de outras áreas.

2. Não será uma retomada de onde paramos. 0 retorno exigirá um plano de ações em diversas frentes e demandará intensa articulação e contextualização local.

3. As respostas ao momento atual podem dar impulso a mudanças positivas e duradouras nos sistemas educacionais. (TODOS PELA EDUCAÇÃO, 2020c) 


\section{JORNAL DE}

\section{Políticas Educacionals}

ISSN 1981-1969

Se o destaque da primeira Nota recaiu sobre o ensino remoto, nesta segunda destaca-se o chamado a um trabalho intersetorial, em que se conjuga a participação governamental, da sociedade civil e do voluntariado, somando esforços entre o público e o privado, como se todos tivessem interesses comuns. Na análise de Fiera, Evangelista e Flores (2020, p. 22), esse discurso objetiva "construir na opinião pública o consenso forjado de unir forças para assegurar o 'direito de aprendizagem' aos 'vulneráveis' por meio do ensino remoto na rede pública de Educação Básica". Além do exposto, a Nota demarca a necessidade da permanência de "elementos das políticas implementadas no momento da pandemia nas redes de ensino de forma permanente constituindo uma espécie de ensino híbrido formado por um mix de ensino presencial e ensino remoto" (HERDADE, 2020, p. 52), o que se articula ao teor da análise da primeira Nota.

Com base em Gramsci (2002), entendemos que, na análise de uma política, precisamos considerar seu processo de construção e identificar sua intencionalidade, desde a formulação até sua aplicação. Ao acompanharmos a atuação do TPE durante o ano de 2020, percebemos claramente seu protagonismo na proposição e coordenação de medidas para o atendimento à educação pública, construindo o consenso em torno da necessidade de atendimento a todos e apontando o ensino emergencial remoto como solução. Embora o TPE não comercialize produtos educacionais, a sua rede de parceiros o faz. E basta uma breve busca virtual nas secretarias de educação sobre sua organização quanto ao ensino remoto para constatarmos a presença das empresas do 'ramo educacional' implantando suas soluções. São fundações nacionais e estrangeiras que aproveitaram a oportunidade da crise e fizeram "uma invasão 'em escala'; sobe pelo esgoto uma parafernália de estratégias para 'mitigar a desigualdade e assegurar a aprendizagem" (FIERA, EVANGELISTA e FLORES, 2020, p. 24).

Destacamos, nesta seção, o protagonismo e a importância do TPE em relação à gestão da educação nesse período de crise bem como a proposição de mudanças nos sistemas com relação à adoção do ensino híbrido, evidenciando sua influência nas políticas educacionais. Mais do que se colocar à frente como possíveis parceiros privados junto ao governo para atuar na educação, esse discurso consolida-os e apresenta o que já 


\section{JORNAL DE Políticas EducacionaIS}

estão ofertando para dar conta desse momento pandêmico.

A seguir, apresentamos as discussões acerca do financiamento e da atuação do TPE na elaboração do Fundeb.

\section{TPE e Fundeb}

O segundo ponto que destacamos neste período de pandemia é a articulação e ação do TPE na elaboração da política pública de financiamento da educação no Brasil, conhecida como Fundeb, cuja vigência estava estipulada até 2020 e precisava de renovação. Esse Fundo, uma das principais fontes de financiamento da educação, sendo responsável por mais de $40 \%$ dos recursos das redes públicas, está assim definido na página do Fundo Nacional de Desenvolvimento da Educação (FNDE):

O Fundo de Manutenção e Desenvolvimento da Educação Básica e de Valorização dos Profissionais da Educação - Fundeb é um fundo especial, de natureza contábil e de âmbito estadual (um fundo por estado e Distrito Federal, num total de vinte e sete fundos), formado, na quase totalidade, por recursos provenientes dos impostos e transferências dos estados, Distrito Federal e municípios, vinculados à educação por força do disposto no art. 212 da Constituição Federal. Além desses recursos, ainda compõe o Fundeb, a título de complementação, uma parcela de recursos federais, sempre que, no âmbito de cada Estado, seu valor por aluno não alcançar o mínimo definido nacionalmente. Independentemente da origem, todo o recurso gerado é redistribuído para aplicação exclusiva na educação básica (FNDE, 2020).

Aqui nosso propósito é resgatar a atuação do TPE no processo de discussão e aprovação da política pública de financiamento, assim não realizaremos análise de conteúdo da legislação aprovada, mas, sim, da capacidade de articulação do Todos e sua influência na formação de consenso e elaboração da política.

Desde 2015, tramitou no Congresso Nacional o Projeto de Emenda Constitucional - PEC 15, que propunha a reformulação do Fundo e a discussão de sua ampliação. Resultou dessa proposta a Emenda Constitucional no 108, aprovada em 27 de agosto de 2020, que transformou o Fundeb em um Fundo permanente, chamado o 'novo Fundeb'. Na 


\section{JORNAL DE}

\section{Políticas EducacionaIS \\ ISSN 1981-1969}

sequência, para garantir a sua funcionalidade, ocorreu a etapa de regularização, por meio de Projetos de Leis que tramitaram no Congresso Nacional, sendo objeto de acirrada disputa e debates acalorados. Desse processo, resultou a Lei no 14.113 , que foi sancionada pelo Presidente da República em 25 de dezembro de 2020.

Como já apontamos em outras vezes 7 , o TPE estava organizado e antecipou-se a essa discussão. Destacamos que, desde 2017, já preparavam o documento “Educação Já: uma proposta suprapartidária de estratégia para educação básica brasileira e prioridades para o governo federal de 2019 a 2022", lançado em 2018, no qual indicavam 7 prioridades, desdobradas em diretrizes, para a educação. A prioridade dois relacionava: "Financiamento mais redistributivo e indutor de qualidade" (TODOS PELA EDUCAÇÃO, 2018, p. 8), enquanto a diretriz nove, por exemplo, propunha, de forma mais direta, "Realizar alterações nos mecanismos de financiamento da educação básica, em especial o Fundeb, tornando-os mais eficientes, redistributivos e indutores de qualidade, visando garantir em todas as redes ao menos condições básicas para a oferta educacional" (Ibidem, p. 69).

O TPE passou a realizar inúmeras atividades para discutir o Fundeb. Caio Callegari, que é coordenador de projetos do Todos, com foco nas políticas de financiamento da educação, em janeiro de 2019, publicou um artigo denominado '2019, o ano em que o Brasil tem que discutir o Fundeb', no qual propõe "mudar a forma como investimos em Educação, com a possibilidade de consolidar um novo desenho, mais inteligente e justo, para o Fundeb" [...] e afirma que, "desde o início de 2016, parlamentares, especialistas e movimentos da sociedade civil como o Todos Pela Educação têm discutido o tema no Congresso Nacional" (CALEGARI, 2019). O TPE chamou essa proposta de Fundeb Equidade, aproximando-se do discurso do BM, que, desde a década de 1990, tem defendido a 'educação com qualidade e equidade' em suas recomendações aos países.

Em março daquele mesmo ano, Caio Callegari participou como palestrante no seminário de formação de gestores municipais de educação organizado pela

\footnotetext{
${ }^{7}$ Ver Bernardi, Uczak, Rossi (2019)
} 


\section{JORNAL DE Políticas Educacionals}

ISSN 1981-1969

Confederação Nacional de Municípios (CNM). O evento, chamado 'CNM Qualifica', ocorreu em Florianópolis (SC) e Porto Alegre (RS), de 18 a 21 de março. Ou seja, além de sua organização interna enquanto movimento, o TPE buscou ampliar sua rede de atuação, dialogando com setores públicos na construção de consensos sobre o novo fundo de financiamento. Nesse processo, criou a importante concordância de que o Fundeb deveria ser transformado em uma política permanente, para que agisse com efeito equalizador e mais justo.

Na página do TPE, o encontro foi assim avaliado por Caio Callegari:

Foi um encontro fundamental para a troca de perspectivas de aprimoramento para o Fundeb entre as duas entidades. 0 Todos Pela Educação e a CNM estão afinados na defesa de propostas que façam o Fundo mais redistributivo, melhorando o quadro de equidade e qualidade dos municípios (TODOS PELA EDUCAÇÃO, 2019a).

Em maio do mesmo ano, o TPE apresentou sua proposta para o novo Fundeb, em evento promovido pelo Ministério da Educação e Ministério da Economia. Entre outras autoridades, estiveram presentes o então Ministro da Educação, Abraham Weintraub, o Secretário-executivo do MEC, Antonio Paulo Vogel, o Secretário da Educação Básica, Janio Carlos Endo, a Subsecretária de Avaliação de Gasto Direto (Ministério da Economia), Aumara de Souza, e os titulares da Comissão de Educação da Câmara dos Deputados, Deputada Professora Dorinha (DEM e Presidente da FPME) e Deputado Gastão Vieira (PROS). Nesse evento, também participaram, apresentando suas propostas para o Fundeb, a Unesco, o IPEA, o BM e o INSPER.

$\mathrm{Na}$ ocasião, ressaltou-se que as propostas para o financiamento da Educação Básica apresentavam-se para além da constituição do novo Fundeb:

Contemplam sugestões para o fortalecimento da transparência dos dados e do controle social, para a criação de mecanismos de indução de qualidade de ensino via incentivos financeiros e para o aperfeiçoamento de outras transferências voluntárias e legais do governo federal"(TODOS PELA EDUCAÇÃO, 2019b). 


\section{JORNAL DE}

\section{Políticas Educacionals}

ISSN 1981-1969

Aqui, além do consenso sobre o fortalecimento do Fundo, aparece a clara proposta de accountability e meritocracia.

O Deputado Federal João Carlos Bacelar (PODE-BA) realizou avaliação sobre a participação do TPE no processo de construção do Fundeb, declarando: “Temos discutido amplamente o Novo Fundeb há três anos. A proposta não é da [deputada federal Prof.] Dorinha Seabra (DEM-TO), é da sociedade brasileira. É também do Todos Pela Educação que participou em todos os momentos e conseguiu emplacar 95\% de suas posições" (Ibidem).

Essa alusão leva-nos a relacionar a ação do Todos junto ao Congresso Nacional desde o início da discussão da PEC 15/15, apresentando suas proposições. Na Figura 1, que segue, podemos verificar um exemplo da intensidade dos encontros realizados para discutir o tema e que culminou com a elaboração e apresentação do documento Educação Já e propostas para a Emenda Constitucional.

Figura1- Encontros promovidos pelo TPE

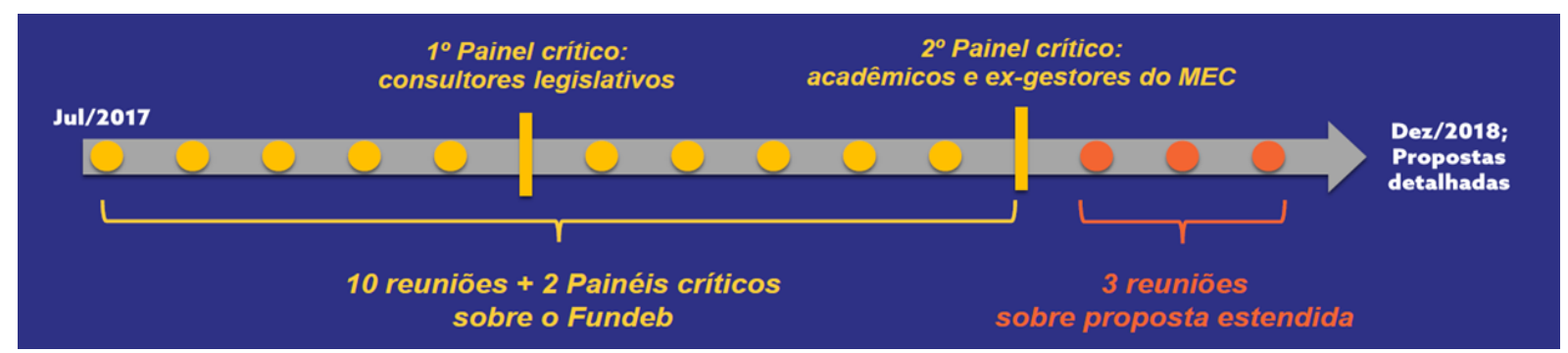

Fonte: TODOS PELA EDUCAÇÃO $(2018$, p.41)

Contudo, foi em 2019 que passou a trabalhar em articulação com a Frente Parlamentar Mista da Educação- FPME -, que reunia 301 deputados e 38 senadores signatários. Em conjunto com a Undime e o Consed, o TPE, o Cenpec e a Fundação Lemann integraram o Conselho Consultivo da Frente, com a missão de movimentar os debates mais urgentes da Educação e dialogar com o Executivo para tirar as prioridades educacionais do papel.

Ainda em 2019, o TPE inaugurou a Casa da Educação, uma nova sede, localizada em Brasília, para alocar a equipe e receber “debates intersetoriais e sobre inovações em 


\section{JORNAL DE Políticas Educacionals}

ISSN 1981-1969

políticas públicas, tendo a Educação como pilar central para o desenvolvimento do País." (TODOS PELA EDUCAÇÃO, 2019c).

A Casa da Educação passou a receber encontros regulares promovidos pela FPME, como o que ocorreu em 11 de setembro de 2019, convocado pela Deputada Dorinha para tratar de detalhes sobre a tramitação do Fundeb (Ibidem). Seguindo sua forma de atuação de ampliar sua rede de relações, o TPE empreendeu também na formação de assessores parlamentares:

Os assessores também têm, nesse espaço, a oportunidade de conhecer mais sobre a Educação Básica. O Programa de Formação em Políticas Educacionais para Assessores Legislativos, promovido pela Diretoria de Estratégia Política do Todos em parceria com a FPME, já teve três edições (IBIDEM).

Em março de 2020, o TPE realizou o painel “2020 chegou. 0 que será do Fundeb?”, do Encontro Anual Educação Já! Participaram desse encontro, o Deputado Federal Bacelar (PODE-BA), Frederico Amâncio (Consed), João Marcelo Borges (TPE), Luiz Miguel Garcia (Undime) e Mansueto Almeida (Secretário do Tesouro Nacional - Ministério da Economia). Na abertura do evento, João Marcelo Borges declarou:

O debate abriu espaço para ampliar o diálogo sobre o principal mecanismo de financiamento da Educação Básica com os atores do Governo Federal, uma vez que o Ministério da Educação (MEC) não tem participado da construção. "Há uma clara desarticulação dentro do governo e o MEC é uma figura ausente, inclusive desse painel" (TODOS PELA EDUCAÇÃO, 2020d).

Esses movimentos do TPE junto ao Congresso evidenciam a ampliação das redes de influência, junto a setores públicos, a instituições representativas da educação e ao parlamento, que é foco deste artigo. Isso não significa a inexistência da correlação de forças no processo de tramitação da legislação sobre o novo Fundeb. Cabe destacar que esse não foi um movimento de mão única, pois observamos a articulação e ação da Campanha Nacional pelo Direito à Educação - CNDE, que reúne diversas entidades ligadas à educação e à sociedade civil organizada, tendo forte atuação também. Aqui não 


\section{JORNAL DE}

\section{Políticas EducacionaIS \\ ISSN 1981-1969}

exploraremos as divergências, disputas ou negociações realizadas por ambos os sujeitos e as diversas instituições que deles participam, pelos limites espaciais do texto.

Em 26 outubro de 2020, após a Aprovação da EC 108 no Congresso, o TPE lançou uma 'Nota Técnica - Lei de Regulamentação do Novo Fundeb', elaborada pelo já mencionado Caio Calegari e por Lucas Hoogerbrugge (líder das relações governamentais do Todos), em que analisaram os projetos de lei apresentados na Câmara - PL 4.372/2020, pela deputada Dorinha (DEM/TO), e, no senado, o PL 4.519/2020, pelo senador Randolfe Rodrigues (REDE/PE). Além de demarcarem os pontos negociados na FPME, o Todos já indicava as discussões que devem ser regulamentadas em legislações complementares e a sua posição sobre quando devem ocorrer:

É importante considerar também, que na visão do Todos pela Educação o prazo para qualquer atualização da lei de regulamentação do Fundeb deve ser o final de 2021, evitando colisão com a agenda eleitoral de 2022 e garantindo maior previsibilidade aos estados e municípios. Portanto precisamos priorizar o essencial para os próximos meses e orientar os pontos em aberto para revisão da lei em 2021. (TODOS PELA EDUCAÇÃO, 2020d, p. 22).

Retomando o processo de tramitação da regulamentação do Fundeb ocorrido em 2020, na Câmara, o relator, Deputado Felipe Rigoni (PSB/ES), encaminhou para votação e aprovação a versão que tinha sido amplamente debatida na FPME, mas que recebeu diversas propostas de emendas, que retomaram a discussão sobre os recursos públicos serem destinados também ao setor privado. Porém, o Senado rejeitou as propostas de emendas aprovadas na Câmara e retomou o projeto original do novo Fundeb em votação no dia 20 de dezembro. Na sequência, o Presidente da República sancionou a Lei no 14.113, de 25 de dezembro de 2020, que regulamentou o Fundo de Manutenção e Desenvolvimento da Educação Básica e de Valorização dos Profissionais da Educação (Fundeb), que passará a vigorar a partir de 2021.

Após essa aprovação da regulamentação no Senado, o TPE assim se manifestou em sua página: 


\section{JORNAL DE Políticas EducacionaIS}

Precisamos ressaltar que o Todos Pela Educação trabalhou fortemente para a construção do texto-base apresentado junto com o Deputado Felipe Rigoni (PSB) e foi contra diversos pontos negativos que, se passassem pelo Congresso, trariam retrocesso e injustiça para a escola pública.

Apesar de termos sido atacados injustamente por grupos específicos, parabenizamos à sociedade pela mobilização e aos parlamentares pela manutenção do texto-base. Foi a resposta adequada e coletiva para vencermos a incapacidade do Governo de dar sua contribuição ao tema ao contrário, o Ministério da Educação (MEC) tem sido um estorvo, atuando contra o Fundeb e todos os avanços necessários para a educação pública (TODOS PELA EDUCAÇÃO, 2020e).

Como já afirmamos, não pretendemos trazer pontos em disputa e nem os elementos aprovados no Fundeb. Focamos, neste estudo, outrossim, na apresentação dos movimentos e das articulações do TPE na discussão e elaboração do novo Fundo de financiamento da educação, o que, como vimos, traz indícios de que continuará no domínio e direção (GRAMSCI, 2002) do processo.

\section{Considerações Finais}

Neste artigo, discutimos o TPE enquanto um movimento de classe que apresenta propostas para a educação brasileira e que tem se fortalecido e atuado de forma hegemônica, operando em várias frentes, na construção de consensos em torno da elaboração de políticas públicas educacionais. Apontamos que os empresários brasileiros fortaleceram-se e ampliaram sua atuação com a criação de novos arranjos, agregando parceiros em rede, como $\mathrm{MNBC}, \mathrm{CNE}$, Observatório PNE e, mais recentemente, na sua relação de Consultoria na Frente Parlamentar Mista da Educação.

Vale considerar, ainda, que compreendemos este momento particular da pandemia mundial com o vírus da COVID-19, em que o processo educacional do País e do mundo viveu a suspensão de aulas presenciais e, consequentemente, o aumento do ensino remoto, como um período que aprofundou as desigualdades socioeconômicas e mostrou concretamente as dificuldades de acesso às tecnologias de comunicação digital para a 


\section{JORNAL DE Políticas Educacionals}

ISSN 1981-1969

maioria da população brasileira. Reconhecemos, nesse contexto, que o momento histórico que é "ao mesmo tempo resultado de processos anteriores e um índice da direção e seu fluxo futuro" (THOMPSON, 1981, p. 58), em que destacamos ação do TPE nesse ano de 2020, não se distancia da sua ação em momentos anteriores na construção de políticas públicas com conteúdos que contemplem seus interesses de classe. Esse movimento empreendido, e que se multiplica entre os empresários do País e suas organizações, tem a intencionalidade de ampliar sua ação na definição de políticas públicas bem como ofertar produtos educacionais, ou seja, na ampliação do setor privado mercantil na educação do País.

Nesse contexto, abordamos dois elementos desse processo de organização e ação do TPE em 2020, quais sejam: a) a reafirmação do TPE através das Notas Técnicas sobre ensino a distância na educação básica frente à pandemia da COVID-19, em que apresentam os fundamentos das possibilidades múltiplas de ensino frente à situação atual da educação no País; e b) as discussões sobre financiamento e atuação do TPE na elaboração do Fundeb, em que destacamos, a partir do Documento Educação Já, a posição e atuação do Todos na elaboração do novo Fundo em que apresentamos a forte presença do movimento nessa política.

Sobre as mudanças na educação no Brasil em 2020, durante o período de pandemia, apresentamos como o Todos rapidamente se organizou, liderou e coordenou a tomada de decisões junto à sociedade e ao Governo, fortalecendo-se frente à opinião pública. Nesse período, houve troca de ministros no MEC e, mesmo se tratando de dois perfis bem diferentes, ambos mantiveram a postura: a omissão na tomada de decisões e coordenação de políticas, papel este estabelecido na legislação. A ausência do MEC na gestão da educação contribuiu muito para que o TPE assumisse e exercesse liderança, sem resistências. Dito de outro modo, ganhou a batalha sem precisar lutar, uma vez que não havia adversário.

Quanto ao conteúdo das Notas Técnicas, o TPE permaneceu fiel seguidor às recomendações dos organismos internacionais, ao indicar o ensino remoto como a única saída para o atendimento aos estudantes. Isso, de fato, foi adotado em larga escala no 


\section{JORNAL DE Políticas Educacionals}

ISSN 1981-1969

Brasil inteiro e abriu um mercado gigantesco para os empresários da educação ofertarem seus pacotes pedagógicos, plataformas digitais, assessoria tecnológica, produtos e serviços negociados com secretarias de educação.

Nas discussões do Fundeb, apresentamos a organização e ação do Todos na elaboração da política com intensa produção de documentos, e a ampliação da sua rede de atuação junto aos parlamentares. Durante cinco anos, o movimento antecipou-se ao debate e forneceu subsídios para a construção de consenso na área educacional na elaboração da política de financiamento. A aprovação do Fundeb foi comemorada pelo TPE, que já inseriu na sua agenda os pontos para continuidade das regulamentações em 2021.

Consideramos mister continuar acompanhando as ações futuras desse sujeito coletivo, que atua como representante da classe empresarial e de seu projeto educacional, que ganhou maior visibilidade junto à opinião da pública em 2020 e construiu consensos em torno da política do novo Fundeb e do ensino remoto na pandemia, amplamente divulgados na mídia. Essas políticas, destacamos, terão desdobramentos num futuro próximo, tanto na manutenção e avanço do ensino remoto quanto na disputa pelos recursos públicos para educação.

\section{Referências}

BALL, S. J. Educação Global S.A.: novas redes políticas e o imaginário neoliberal. Ponta Grossa: UEPG, 2014.

BERNARDI, L. M.; UCZAK, L. H.; ROSSI, A. J. As relações do Estado com empresários nas políticas educacionais: PDE/PAR e Guia de Tecnologias Educacionais. In: PERONI, V. M. V. (org). Diálogos sobre as redefinições do papel do Estado e nas fronteiras entre o público e o privado na educação. São Leopoldo: Oikos, 2015, p. 52-71.

BERNARDI, L. M.; UCZAK, L. H.; ROSSI, A. J. Relações do movimento empresarial na política brasileira: a naturalização da associação público privada. In: PERONI, V. M. V.; LIMA, P. V. de; KADER, C. R. (org). Redefinições das fronteiras entre o público e o privado: implicações para a democratização da educação. São Leopoldo: Oikos, 2018, p. 115- 124. 


\section{JORNAL DE Políticas Educacionals}

ISSN 1981-1969

BERNARDI. L. M.; UCZAK, L. H.; ROSSI, A. J. Relações do Movimento Empresarial na Política Educacional Brasileira: a discussão da Base Nacional Comum. Currículo Sem Fronteiras, v. 18-n.1, p. 29, 2018b. Disponível em: < https://www.curriculosemfronteiras.org/vol18iss1articles/bernardi-uczak-rossi.html> Acesso em: 18 out. 2019.

CALLEGARI, C. 2019: o ano em que o Brasil tem que discutir o Fundeb. Estadão, 22 de janeiro de 2019. Disponível em: https://educacao.estadao.com.br/blogs/educacao-eetc/2019-o-ano-em-que-o-brasil-tem-que-discutir-o-fundeb/. Acesso em: 12 nov. 2020.

FIERA, L.; EVANGELISTA, 0.; FLORES, R. Chantagem como estratégia para assegurar o "direito de aprendizagem" aos "vulneráveis". In: SOARES et al. Coronavírus, educação e luta de classes no Brasil. $1^{\mathrm{a}}$ ed. Brasil: Terra Sem Amos, 2020, v. I, p. 21-27.

FNDE - Fundo Nacional de Desenvolvimento da Educação. 2020. Disponível em: https://www.fnde.gov.br/financiamento/fundeb. Acesso em: 30 dez. 2020

GRAMSCI, A. Cadernos do Cárcere. Vol. 3. 3aㅡ Ed. Rio de Janeiro: Civilização Brasileira, 2002.

HERDADE, L. Todos pela Educação? classe dominante e poder frente à pandemia. In: LAMOSA, R. (org). Classe dominante e educação em tempos de pandemia: uma tragédia anunciada. Editora Terra sem Amos: Parnaíba, 2020, p. 47-54.

ROSSI, A. J; BERNARDI, L. M.; UCZAK, L. H. Relações entre Estado e empresários no PDE/PAR: algumas contradições na política educacional brasileira. Revista Brasileira de Política e Administração da Educação, v. 33, p. 355, 2017.

SHIROMA, E. O.; GARCIA, R. M. C.; CAMPOS, R. F. Conversão das "almas" pela liturgia da palavra: uma análise do movimento Todos pela Educação. In: BALL, S. J.; MAINARDES, J. Políticas educacionais: questões e dilemas. São Paulo: Cortez, 2011. p. 222-248

THOMPSON, E. P. A Miséria da Teoria ou um Planetário de Erros: uma crítica ao pensamento de Althusser. Rio de Janeiro: Zahar Editores, 1981.

TODOS PELA EDUCAÇÃO. Todos Pela Educação apresenta proposta de Fundeb Equidade para a CNM. 2019a. Disponível em: https://todospelaeducacao.org.br/noticias/todos-pela-educacao-apresenta-propostade-fundeb-equidade-para-cnm/. Acesso em: 12 nov. 2019.

TODOS PELA EDUCAÇÃO.Todos pela Educação apresenta proposta para novo fundeb em evento promovido pelo ministério da educação e ministério da economia. 2019b. Disponível em: https://todospelaeducacao.org.br/noticias/todos- 


\section{JORNAL DE Políticas EducacionaIS}

ISSN 1981-1969

pela-educacao-apresenta-proposta-para-novo-fundeb-em-evento-promovido-peloministerio-da-educacao-e-ministerio-da-economia/. Acesso em: 10 nov. 2019.

TODOS PELA EDUCAÇÃO. Sede do Todos em Brasília promove debates sobre educação. 2019c. Disponível em: https://todospelaeducacao.org.br/noticias/casa-daeducacao-sede-do-todos-em-brasilia-promove-debates-sobre-educacao/. Acesso em: 22 set. 2020 .

TODOS PELA EDUCAÇÃO. Educação na frente: temos uma frente parlamentar mista da educação - entenda por que ela é importante para estados e municípios. 2019.

Disponível em: $<$ https://todospelaeducacao.org.br/noticias/educacaonafrente-temosuma-frente-parlamentar-mista-da-educacao-entenda-por-que-ela-e-importante-paraestados-e-municipios/>. Acesso em: 12 nov. 2019.

TODOS PELA EDUCAÇÃO. 2020 chegou. 0 que será do Fundeb? 2020d. Disponível em: https://todospelaeducacao.org.br/noticias/2020-chegou-o-que-sera-do-fundeb/.

Acesso em: 28 dez. 2020.

TODOS PELA EDUCAÇÃO. Educação Já. 2018. Disponível em:

www.todospelaeducacao.org.br/ uploads/ posts/170.pdf. Acesso em: 18 mar. 2020.

TODOS PELA EDUCAÇÃO. Diálogos com CNE: a educação frente à pandemia. Webinário. 2020a. Disponível em: <http://tiny.cc/dlnuoz>. Acesso em: 18 dez. 2020.

TODOS PELA EDUCAÇÃO. Ensino a distância na Educação Básica frente à pandemia da Covid-19. Nota Técnica. 2020b. Disponível em: <https://bit.ly/3aTZjSd>. Acesso em: 16 dez. 2020.

TODOS PELA EDUCAÇÃO. O Retorno às aulas presenciais no contexto da Pandemia da Covid-19. Nota Técnica. 2020c. Disponível em: < https://www.todospelaeducacao.org.br/_uploads/_posts/433.pdf?1194110764>. Acesso em: 16 dez. 2020.

TODOS PELA EDUCAÇÃO. Lei de regulamentação do novo Fundeb. Nota Técnica 2020d. Disponível em: https://todospelaeducacao.org.br/wordpress/wpcontent/uploads/securepdfs/2020/11/Posicionamento-TPE Lei-Fundeb 07 11-1.pdf. Acesso em: 30 de dez. 2020

TODOS PELA EDUCAÇÃO. Vitória da educação! novo fundeb, maior, melhor e mais justo, funcionando em 2021! 2020e. Disponível em:

https://todospelaeducacao.org.br/noticias/vitoria-da-educacao-novo-fundeb-maiormelhor-e-mais-justo-funcionando-em-2021/. Acesso em: 20 dez. 2020. 


\section{JORNAL DE Políticas EducacionaIS \\ ISSN 1981-1969}

UCZAK, L. H.; BERNARDI, L. M.: ROSSI, A. J. Organização e ação da classe empresarial na educação brasileira. In PERONI, V. M. V. et al. (Org) Anais do $2^{\circ}$ seminário redefinições das fronteiras entre o público e o privado: Implicações para a democratização da educação. Porto Alegre: UFRGS, 2019. p. 271-275.

UCZAK, L. H.; BERNARDI, L. M.: ROSSI, A. J. O governo Temer e a asfixia dos processos de democratização da educação. Revista Educação UFSM. v. 45, 2020 - Jan./Dez.

Disponível em: <https://periodicos.ufsm.br/reveducacao/issue/view/1544> Acesso em: 18 abr. 2020

WOOD, Ellen Meiksins. Democracia contra capitalismo: a renovação do materialismo histórico. São Paulo: Boitempo Editorial, 2003. 


\section{JORNAL DE PoLíticas EducacionaIS \\ ISSN 1981-1969 \\ Volume 15 \\ Número 38 \\ 26 de agosto de 2021}

(c)

SORE RIGHIS RESERVED O Copyright é retido pelo/a autor/a (ou primeiro co-autor) que outorga o direito da primeira publicação ao Jornal de Políticas Educacionais. Mais informação da licença de Creative Commons encontram-se em https://creativecommons.org/licenses/by-nc-nd/4.0. Qualquer outro uso deve ser aprovado em conjunto pelo/s autor/es e pelo periódico.

JoRnal DE Políticas EdUCACIONAIS é uma publicação do Núcleo de Políticas Educacionais do Setor de Educação da Universidade Federal do Paraná - NuPE/UFPR, em consórcio com a Linha de Pesquisa em Políticas Educacionais do Programa de Pós-Graduação em Educação - PPGE/UFPR, que aceita colaboração, reservando-se o direito de publicar ou não o material espontaneamente enviado à redação. As colaborações devem ser enviadas ao NuPE/UFPR, conforme orientações contidas nas páginas do periódico na internet: http://revistas.ufpr.br/jpe.

\section{INDEXAÇ̃̃O:}

BASE DE DADOS
Sumário.Org
Google Scholar
BASE
Dimensions
Miar

DIRETÓRIOS
Scielo Educ@
Diadorim
DOAJ
Erih Plus
Latindex
EZB
ROAD
Journal 4-free

ÍNDICES
Index Copernicus
Cite Factor
PORTAIS
LiVre
Capes
Science Open
World Wide Science

(Periódico integralmente disponível apenas em via eletrônica)

Jornal de Políticas Educacionais / Núcleo de Políticas Educacionais da Universidade Federal do Paraná -

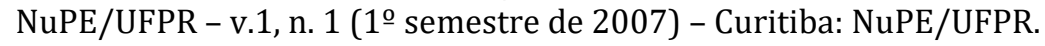

Volume 15, número 38- Agosto de 2021

ISSN 1981-1969

1. Educação - Periódicos. 2. Política Educacional - Periódicos. I. NuPE/UFPR 


\section{JORNAL DE Políticas EducacionaIS

Comitê Editorial:

Elisângela Scaff (UFPR)

Daniela de Oliveira Pires (UFPR)

Conselho Editorial:

Adriana Aparecida Dragone Silveira (UFPR-Brasil), Ana Lorena de Oliveira Bruel (UFPR-Brasil), Andréa Barbosa Gouveia (UFPR - Brasil), Angela Maria Martins (FCC, Brasil), Angelo Ricardo de Souza (UFPRBrasil), Antonia Almeida Silva (UEFS, Brasil), Cassia Alessandra Domiciano (UFPR-Brasil), Cesar Tello (Universidad Nacional Tres Febrero, Argentina), Claudia Regina Baukat Silveira Moreira (UFPR-Brasil), Cristiane Machado (Unicamp- Brasil), Elton Luiz Nardi (UNOESC, Brasil), Fernanda Saforcada (Universidad de Buenos Aires - UBA - Argentina), Isaac Paxe (Instituto Superior de Ciências da Educação (ISCED- Luanda, Angola), Gabriela Schneider (UFPR-Brasil), Gladys Beatriz Barreyro (USP - Brasil), Gilda Cardoso Araújo (UFES - Brasil), Gustavo Enrique Fischman (Arizona State University - USA), Janete Maria Lins de Azevedo (UFPE, Brasil), Jefferson Mainardes (UEPG - Brasil), João Ferreira de Oliveira (UFG - Brasil), Jorge Alarcon Leiva (Universidad de Talca - Chile), Jorge Manuel Gorostiaga (UNSAM - Argentina), Juca Gil (UFRGS Brasil), Luciana Rosa Marques (UFPE, Brasil), Marcos Alexandre dos Santos Ferraz (UFPR-Brasil) Marcia Aparecida Jacomini (Unifesp-Brasil), Maria Dilnéia Espíndola Fernandes (UFMS, Brasil), Natalia Oliveira Woolley (UCLA, USA), Ney Cristina Monteiro de Oliveira (UFPA - Brasil), Nicolás Bentancur, (Universidad de la República de Uruguay), Nora Krawczyk (Unicamp- Brasil), Pedro Flores-Crespo (UAQ, México) Rodrigo da Silva Pereira (UFBA, Brasil), Robert Verhine (UFBA - Brasil), Rosana Cruz (UFPI - Brasil), Rubens Barbosa Camargo (USP - Brasil), Sebastián Donoso Díaz (Universidad de Talca - Chile), Theresa Adrião (UNICAMP Brasil), Vera Maria Vidal Peroni (UFRGS - Brasil).

Créditos e Agradecimentos:

Revisão de Língua Portuguesa, Abstract e Resumen: Programa de apoio às publicações científicas periódicas da UFPR

Arte e diagramação: Tiago Tavares (tiagotav@gmail.com)

Jornal de Políticas Educacionais

Universidade Federal do Paraná

Setor de Educação

Núcleo de Políticas Educacionais - NuPE/UFPR

Avenida Sete de Setembro, 2645

$2^{\circ}$ andar, Sala 213

80.230-010 - Curitiba - PR - Brasil

Tel.: 41-3535-6264

jpe@ufpr.br

http://revistas.ufpr.br/jpe 